\title{
Beyond Good Intentions: The Role of the Building Passport for the Sustainable Conservation of Built Heritage to Behavioural Change
}

\author{
Joana dos Santos Gonçalves ${ }^{1,2}, * \mathbb{D}$, Ricardo Mateus ${ }^{1} \mathbb{D}$, José Dinis Silvestre ${ }^{3} \mathbb{D}$ and Ana R. Pereira Roders ${ }^{2} \mathbb{D}$ \\ 1 ISISE-School of Engineering, Department of Civil Engineering, University of Minho, Campus de Azurém, \\ 4800-058 Guimarães, Portugal; ricardomateus@civil.uminho.pt \\ 2 AE+T—Faculty of Architecture and the Built Environment, Delft University of Technology, Julianalaan 134, \\ 2628 BL Delft, The Netherlands; A.R.Pereira-Roders@tudelft.nl \\ 3 CERIS-Instituto Superior Técnico, Universidade de Lisboa, Av. Rovisco Pais, 1049-001 Lisboa, Portugal; \\ jose.silvestre@tecnico.ulisboa.pt \\ * Correspondence: j.m.goncalves@tudelft.nl
}

Citation: dos Santos Gonçalves, J.; Mateus, R.; Silvestre, J.D.; Roders, A.R.P. Beyond Good Intentions: The Role of the Building Passport for the Sustainable Conservation of Built Heritage to Behavioural Change. Sustainability 2021, 13, 8280.

https://doi.org/10.3390/su13158280

Academic Editor: Asterios Bakolas

Received: 10 May 2021

Accepted: 19 July 2021

Published: 24 July 2021

Publisher's Note: MDPI stays neutral with regard to jurisdictional claims in published maps and institutional affiliations.

Copyright: (c) 2021 by the authors. Licensee MDPI, Basel, Switzerland. This article is an open access article distributed under the terms and conditions of the Creative Commons Attribution (CC BY) license (https:// creativecommons.org/licenses/by/ $4.0 /)$.
Abstract: Despite the recognised importance of built heritage for sustainable development, and the multiple tools, recommendations, guidelines, and policies developed in recent years to support decision-making, good sustainable conservation practices often fail to be implemented. Challenges faced by practitioners often relate to external factors, and there is a gap in the understanding of the role of the nature of the designer and the behavioural dimension of the challenges in implementation. This research applies the Theory of Planned Behaviour (TPB) to verify how a building passport for sustainable conservation (BPSC) impacts design students' intentions and actual design decisions towards built heritage conservation. This research aims to ascertain the role of the BPSC to affect attitudes, subjective norms, and intentions and ultimately change conservation behaviours. The results show that this tool has a positive contribution to reinforce existing attitudinal beliefs. Still, no significant changes were found in the overall conservation behaviours, suggesting that beliefs hindering implementation may more often be related to aesthetic reasons, creativity and innovation, and program requirements, than with beliefs regarding the sustainable performance of the building. This study demonstrates that using the TPB to analyse design processes in the context of built heritage is an innovative methodological approach that contributes to a deeper understanding of the psychological factors affecting sustainability and built heritage conservation decisions.

Keywords: behavioural intentions; built environment; heritage; sustainability; conservation; building passport; theory of planned behaviour

\section{Introduction}

Recognising that heritage conservation is becoming increasingly relevant for sustainable development $[1,2]$, tools to support decision-making have been developed in recent decades to encourage design decisions to further integrate sustainability principles in built heritage conservation, including economic aspects, cultural significance, and environmental performance [3-5]. Regulations, recommendations of best practices, and principles for intervention have been established internationally [6-11]. However, as the Council of Europe report warned, "It is not sufficient simply to formulate principles; they must also be applied" [12]. Therefore, if we have the tools, and sustainable conservation is widely promoted as best practice, why is sustainable conservation still lacking application or failing when tried?

Literature addressing the challenges faced by practitioners in the built heritage conservation consistently pointed out external factors, such as the lack of knowledge and technical capacity of the different stakeholders [13-16] behind the performance gap between conservation intentions and its actual implementation in the design and construction stages. 
Seldom, the nature of the designer and the behavioural dimension of these challenges, underlying socio-psychological factors, have been found discussed in the literature [17].

In the field of psychology, the Theory of Planned Behaviour (TPB) [18-20] is one of the most complete sociopsychological models of behaviour, correlating intentions with actually performed behaviours, by considering the effect of intervening events, such as low behavioural control, and facilitating conditions, such as attitudes (personal evaluative dispositions). This theory, in particular, has been used to predict and understand behaviours in the scope of health [21-24], consumption [25,26], or entrepreneurship $[27,28]$, for instance. In addition, in the context of a more sustainable built environment, the TPB has been used to analyse users' behaviours in relation to green labels [29], recycling behaviours [30], or energy consumptions [31]. In the heritage sector, studies using the TPB commonly address factors affecting tourists' destination choices [32-34] and residents' support of tourism development [35]. The TPB has also been used to analyse designers' decisions regarding sustainability, such as the factors affecting designers' choices to specify sustainable materials [36,37], or to adopt strategies towards construction waste minimisation [38], highlighting the significant role of attitudes as predictors of designers' behaviours.

Earlier research with design students used the Theory of Planned Behaviour (TPB) to measure the gap between conservation intentions and decision behaviours. By focusing on design students, this study allowed isolation of the internal factors affecting decisions in an environment with higher levels of Perceived Behavioural Control (PBC). It demonstrated that the dissonance between conservation intentions and conservation behaviours persisted, and identified the role of attitudes as one of the main factors affecting the implementation of conservation intentions by design students during build heritage conservation projects [39]. The results also show that, despite all the current literature on the contributions of heritage to sustainable development, the compatibility with sustainability standards is still one of the most salient beliefs hindering the implementation of intentions [39].

As identified by Lee et al. [37], targeting the attitudes of the designers towards sustainable practices is critical. Literature shows that education and persuasive communication have an essential role in a behavioural change towards sustainable conservation [17], contributing to tackling knowledge and belief gaps [40], increasing awareness, and raising positive attitudes [41], and consequently leading to changing behaviour-relevant beliefs, affecting the formation of intentions and their implementation [42]. There was consensus on the role of alternative events that require active participation and are directed at primary beliefs identified in the research population towards the target behaviour [42].

Based on these recommendations, a sustainability assessment tool specifically designed for the baseline assessment of heritage buildings was developed-the Building Passport for Sustainable Conservation (BPSC) [43]. The present research uses the TPB to test how it can contribute to a behavioural change towards a more sustainable conservation of built heritage, by targeting attitudes regarding the sustainability of built heritage. The BPCS was applied by the research population, with the ambition to strengthen positive beliefs towards the values of built heritage and reverse the former beliefs on the incompatibility between heritage conservation and sustainability, previously identified [39]. This paper presents measures of the effects of the application of the BPCS on design students' intentions and behaviours towards a sustainable conservation of built heritage.

\section{Materials and Methods}

\subsection{TACT: Target, Action, Context, and Time}

This study applies the theory of planned behaviour (TPB) to analyse the effect of the building passport for sustainable conservation in design intentions and decisions. It is based on a sequence of four steps, starting with the building survey and value assessment, followed by an intention questionnaire, the generative artefacts, with participants expressing visually and spatially their priorities through design, and finally self-assessment of behaviour, as represented in the diagram in Figure 1. 


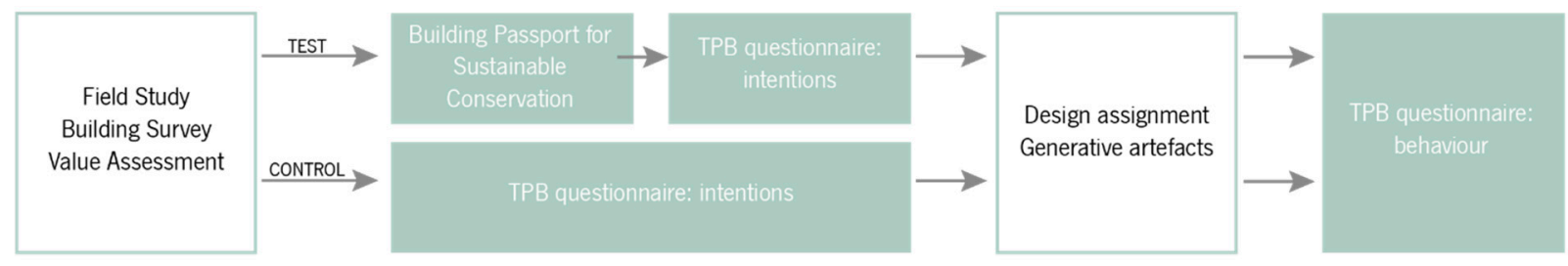

Figure 1. Diagram representing the sequence of steps of the study.

The target population were architecture students of the Heritage \& Architecture design studios, offered by the faculty of Architecture and the Built Environment, at the Delft University of Technology, the Netherlands. By focusing on design students instead of practitioners, this methodology aims at isolating and identifying internal behavioural factors affecting decisions on built heritage conservation in a context with more creative freedom, less obligation of complying with norms, and reduced interaction with multiple stakeholders.

This study took place between May 2020 and July 2020. The students were asked to give informed consent to start the survey. The questionnaire was distributed among 39 students. A return rate of $90 \%$ was achieved (see Table 1). The sample population was divided into two groups: the test group, with 20 students, used the building passport, and the control group, with 19 students, answered the intention questionnaire without using the building passport. Both groups worked on a hypothetical design assignment for the conservation and adaptive reuse of the Priorij Emmaus, in Maarsen, Utrecht, the Netherlands. The Priorij Emmaus [44] is a 20th century monastery, designed by Jan de Jong in 1964, listed as a national monument since 2016.

Table 1. Response rate.

\begin{tabular}{lllll}
\hline & Students on List & Responses Phase 1 & Responses Phase 2 & Response Rate \\
\hline (1) Test group & 20 & 20 & 18 & $90 \%$ \\
(2) Control group & 19 & 19 & 17 & $89.5 \%$ \\
Total & 39 & 35 & $90 \%$ & \\
\hline
\end{tabular}

In the development of the intention survey, the behaviour of interest was defined in its Target, Action, Context, and Time (TACT) elements [42,45]. Context and Time are common to all groups of questions, referring to the specific building used as a case study in the design studios. Target and Action refer to the conservation actions towards the valuable attributes of a building, considering conservation as the actual action of preserving and keeping a specific building element. The building's attributes were defined as in the building passport, following the seven building layers adapted by Kuipers and de Jonge [46]: site (relation with context and surroundings); skin (building envelope); structure (load-bearing support systems); services (technical infrastructures such as plumbing or HVAC); space plan (layout and interior spaces); stuff (furnishings and furniture); and spirit of the place (building's meanings over time). The layer "stuff" was not included in the building passport since no core indicators for sustainability were related with it, and as a result, it was also excluded from the TPB questionnaire.

\subsection{Development of the Intention-Behaviour Questionnaire}

This study applied the intention-behaviour questionnaire developed in a previous study [39], based on the psychological constructs of the Theory of Planned Behaviour [18-20]. The TPB questionnaire was developed in a previous study [39] that adapted the instrument developed by Ajzen [45] to the specificities of built heritage conservation. The questionnaire contains four groups of questions: (1) attitudes ("I consider the conservation (of element $x$ ) to be"), (2) subjective norms ("is expected of me that I conserve (element x)"), (3) perceived behavioural control ("it is easy for me to conserve (element $x$ )"), and (4) intention ("I intend 
to conserve (element $\mathrm{x}$ )"), where "element $\mathrm{x}^{\prime \prime}$ refers to building attributes on each building layer, according to the BPSC. All the questions use a 5-point Likert scale to assess the theory's major psychological constructs through direct measures using previously validated scales (valuable/worthless, likely/unlikely, agree/disagree, etc.). The questionnaire is provided in the Supplementary Materials.

In the first group, the questions aimed at identifying the participants' attitudes towards the building's attributes, determining their favourable or unfavourable personal evaluations about the act of keeping those attributes. The second group aims to identify social pressure over the performance of conservation actions, referring to beliefs about normative and social expectations. In the third group, the questions aimed at measuring the perceived behavioural control of participants. Finally, in the fourth group, standard direct measures of intention were collected for each attribute of the building to establish a baseline for comparison with the final design interventions.

In the follow-up questionnaire, students were asked to self-assess their designs (i.e., "in my design I decided to conserve (element $x)^{\prime \prime}$ ), reporting on the level of conservation of the same list of attributes in a similar 5-point Likert scale.

\subsection{Data Analysis}

Data were analysed using SPSS Version 26.0 (SPSS Inc., Chicago, IL, USA). Descriptive statistics, including percentages, arithmetic means, and standard deviation, were used to summarise the sustainability assessment results using the building passport. Descriptive statistics were also used to summarise the results of the intention-behaviour questionnaire regarding attitudes, subjective norms, perceived behavioural control, intentions, and behaviours of the students towards the conservation of each building attribute.

This questionnaire was validated for reliability and internal consistency, measuring the Cronbach alpha for each variable group (attitude, subjective norms, perceived behavioural control (PBC), intention, and behaviour), with alpha being higher than 0.6 in all cases (Table 2), as recommended by the literature $[47,48]$. Considering that the questionnaire proved to be internally consistent, data were merged into the main variable groups to run the bivariate correlation analysis with a sufficient sample.

Table 2. Internal consistency and reliability of the measuring scales.

\begin{tabular}{lll}
\hline & Cronbach's Alpha & No. of Items \\
\hline Attitudes & 0.721 & 20 \\
Subjective norms & 0.804 & 20 \\
PBC & 0.781 & 20 \\
Intention & 0.783 & 20 \\
Behaviour & 0.806 & 20 \\
\hline
\end{tabular}

The Kolmogorov-Smirnov test was used to verify the normality of the distribution, confirming a significant deviation of responses in the research population $(p<0.05)$. As such, non-parametric Mann-Whitney tests were preferred instead of independent sample $t$-tests to compare the means of the two analysed groups.

The relation between behaviour and the other variables was analysed using linear regression modelling, followed by multiple regression with backwards elimination. The final model was obtained by eliminating variables associated with a $p$-value greater than 0.1 , with low statistical significance. Collinearity among variables in the model was measured by the variance inflation factor (VIF). No multicollinearity was detected (VIF $<2$ ). Results are expressed using the Beta coefficient with their confidence intervals at $95 \%$ (95\% Cis).

In the last question of the self-assessment questionnaire, respondents were asked to identify the main reason for not keeping their previously expressed attributes. The results of this question were analysed qualitatively, using content and thematic analysis. 


\section{Results}

\subsection{Descriptive Statistics}

In the test group, results show a predominance of neutral or negative attitudes towards the conservation of the building (around 52\% of the responses) and low levels of perception of control (pointed out by about $55 \%$ of the respondents), as presented in Table 3 . The low average values are primarily due to the layer "services" that concentrates only on negative beliefs. This layer has the lowest values: attitudes regarding its conservation are shallower (with only 13\% of positive responses) than the conservation of other layers, and intentions and self-reported behaviours are not positive for more than $80 \%$ of participants. On the other extreme, the layer "structure" presents high average replies, with positive attitudes (86\%) and perception of high expectations, but also good levels of control (for $67 \%$ of respondents). Moreover, the layer "skin" has consistently positive responses, with 74\% of the respondents expressing positive attitudes and $72 \%$ expressing positive intentions towards its conservation. Finally, in the layer "Spirit of the Place", there is a positive attitude towards conservation, but it presents the lowest value on the perceived levels of control.

Table 3. Average values according to building layer in the test group.

\begin{tabular}{|c|c|c|c|c|c|c|c|c|c|c|}
\hline \multirow[b]{2}{*}{ Layer } & \multicolumn{2}{|c|}{ Attitudes ${ }^{1}$} & \multicolumn{2}{|c|}{ Subj. Norms $^{2}$} & \multicolumn{2}{|c|}{$\mathrm{PBC}^{3}$} & \multicolumn{2}{|c|}{ Intention $^{4}$} & \multicolumn{2}{|c|}{ Behaviour $^{5}$} \\
\hline & Pos. & $\begin{array}{l}\text { Mean } \\
(\mathrm{SD})\end{array}$ & High & $\begin{array}{l}\text { Mean } \\
\text { (SD) }\end{array}$ & High & $\begin{array}{l}\text { Mean } \\
\text { (SD) }\end{array}$ & Pos. & $\begin{array}{l}\text { Mean } \\
\text { (SD) }\end{array}$ & Pos. & $\begin{array}{l}\text { Mean } \\
\text { (SD) }\end{array}$ \\
\hline Site & $60 \%$ & $2.3(1.0)$ & $49 \%$ & $2.5(1.1)$ & $57 \%$ & $2.4(1.0)$ & $60 \%$ & $2.3(1.0)$ & $76 \%$ & $2.1(1.1)$ \\
\hline Structure & $86 \%$ & $1.9(0.6)$ & $76 \%$ & $2.1(0.8)$ & $67 \%$ & $2.2(0.9)$ & $79 \%$ & $1.9(0.7)$ & $86 \%$ & $1.8(0.7)$ \\
\hline Skin & $74 \%$ & $2.1(0.9)$ & $73 \%$ & $2.1(0.9)$ & $66 \%$ & $2.2(0.9)$ & $72 \%$ & $2.1(0.9)$ & $69 \%$ & $2.0(1.0)$ \\
\hline Services & $13 \%$ & $3.7(1.0)$ & $16 \%$ & $3.9(1.1)$ & $40 \%$ & $2.9(1.0)$ & $18 \%$ & $3.6(1.0)$ & $17 \%$ & $3.6(1.2)$ \\
\hline Space Plan & $55 \%$ & $2.3(1.0)$ & $48 \%$ & $2.5(1.1)$ & $45 \%$ & $2.5(0.9)$ & $55 \%$ & $2.4(1.0)$ & $50 \%$ & $2.6(1.1)$ \\
\hline Spirit of the Place & $64 \%$ & $2.2(0.9)$ & $51 \%$ & $2.5(0.9)$ & $38 \%$ & $2.7(1.0)$ & $64 \%$ & $2.3(1.0)$ & $50 \%$ & $2.6(1.0)$ \\
\hline Average & $48 \%$ & $2.4(0.9)$ & $43 \%$ & $2.5(1.0)$ & $45 \%$ & $2.5(1.0)$ & $47 \%$ & $2.4(1.0)$ & $47 \%$ & $2.5(1.0)$ \\
\hline
\end{tabular}

1 on a scale from 1-5 where 1 is "very valuable" and 5 is "worthless"; $2 / 4$ on a scale from $1-5$ where 1 is "extremely likely" and 5 is

"extremely unlikely"; ${ }^{3}$ on a scale from $1-5$ where 1 is "strongly agree" and 5 is "strongly disagree"; ${ }^{5}$ on a scale from $1-5$ where 1 is " $100 \%$ " and 5 is " $\sim \%$ ".

At the attribute level, the results allow identifying the most valued attributes of the building and the priorities in the design (Table 4). The conservation of the structural system, for instance, is seen for $86 \%$ of the respondents in the test group as valuable, and $100 \%$ feel social pressure to conserve this element, despite the low levels of perceived behavioural control (57\% positive responses). As a result, $89 \%$ of the respondents selfreport high percentages of conservation of the structural system. Other indicators with similar positive reactions are the structural materials, the façade, and the building shape. In the opposite direction, the conservation of the layer "services" concentrates more negative reactions, with the indicators energy and heating, ventilation, and water presenting the lowest attitudes, intentions, perceived control, and self-reported conservation behaviours. At the same time, more than half of the respondents do not feel social pressure for the conservation of this layer. These results show that the services layer is the least conserved by the design students in the case study.

In the control group, the descriptive statistics show results very similar to the test group, with slightly lower perception of control (40\% positive responses, instead of $45 \%$ ) and social pressure ( $41 \%$ instead of $43 \%$ ). On average, levels of attitude, intention, and behaviour do not vary significantly between the two groups. As in the first group, the layer "structure" consistently presents positive replies but is surpassed in the control group by the layer "space plan", with $87 \%$ positive attitudes, $68 \%$ high perceived norms, and $63 \%$ of perceived control (Table 5). This is a significant difference from the test group, where positive attitudes towards the conservation of the layer "space plan" are expressed by only $55 \%$ of participants. The layer "services" has even lower results in the control group, with 
only $4 \%$ positive attitudes. Despite this, frequencies of intention and behaviour towards "services" are similar in both groups. In the control group, participants express a very low level of perceived behavioural control in relation to the layer "services" (14\% positive responses).

Table 4. Main positive and negative indicators in the test group.

\begin{tabular}{|c|c|c|c|c|c|c|c|c|c|c|c|}
\hline & \multirow[b]{2}{*}{ Indicator } & \multicolumn{2}{|c|}{ Attitudes ${ }^{1}$} & \multicolumn{2}{|c|}{ Subj. Norms ${ }^{2}$} & \multicolumn{2}{|c|}{ PBC $^{3}$} & \multicolumn{2}{|c|}{ Intention ${ }^{4}$} & \multicolumn{2}{|c|}{ Behaviour $^{5}$} \\
\hline & & Freq. & $\begin{array}{l}\text { Mean } \\
\text { (SD) }\end{array}$ & Freq. & $\begin{array}{l}\text { Mean } \\
\text { (SD) }\end{array}$ & Freq. & $\begin{array}{l}\text { Mean } \\
\text { (SD) }\end{array}$ & Freq. & $\begin{array}{l}\text { Mean } \\
\text { (SD) }\end{array}$ & Freq. & $\begin{array}{l}\text { Mean } \\
\text { (SD) }\end{array}$ \\
\hline \multirow{3}{*}{ positive } & $\begin{array}{l}\text { Structural } \\
\text { System }\end{array}$ & $86 \%$ & $1.9(0.6)$ & $100 \%$ & $2.1(0.8)$ & $57 \%$ & $2.4(1.1)$ & $71 \%$ & $2.1(0.7)$ & $89 \%$ & $1.7(0.7)$ \\
\hline & $\begin{array}{l}\text { Structural } \\
\text { Materials }\end{array}$ & $86 \%$ & $1.9(0.6)$ & $95 \%$ & $2.1(0.8)$ & $76 \%$ & $2.1(0.8)$ & $86 \%$ & $1.8(0.7)$ & $84 \%$ & $1.9(0.6)$ \\
\hline & Façade & $91 \%$ & $1.5(0.8)$ & $86 \%$ & $1.4(0.6)$ & $71 \%$ & $2.0(0.9)$ & $91 \%$ & $1.8(0.9)$ & $78 \%$ & $1.8(1.2)$ \\
\hline \multirow{3}{*}{ negative } & $\begin{array}{l}\text { Energy and } \\
\text { heating }\end{array}$ & $81 \%$ & $3.7(1.2)$ & $75 \%$ & $3.9(1.2)$ & $76 \%$ & $3.4(1.0)$ & $76 \%$ & $3.6(1.2)$ & $89 \%$ & $3.8(1.2)$ \\
\hline & Ventilation & $95 \%$ & $4.0(0.9)$ & $50 \%$ & $3.9(1.1)$ & $67 \%$ & $2.1(0.9)$ & $95 \%$ & $3.9(0.9)$ & $72 \%$ & $3.6(1.1)$ \\
\hline & Water & $86 \%$ & $3.5(0.9)$ & $54 \%$ & $3.8(1.1)$ & $67 \%$ & $3.1(1.1)$ & $76 \%$ & $3.3(1.0)$ & $89 \%$ & $3.4(1.4)$ \\
\hline
\end{tabular}

1 on a scale from $1-5$ where 1 is "very valuable" and 5 is "worthless"; ${ }^{2 / 4}$ on a scale from $1-5$ where 1 is "extremely likely" and 5 is "extremely unlikely"; ${ }^{3}$ on a scale from $1-5$ where 1 is "strongly agree" and 5 is "strongly disagree"; 5 on a scale from $1-5$ where 1 is " $100 \%$ " and 5 is " $\sim \% "$.

Table 5. Average values according to building layer in the control group.

\begin{tabular}{lllllllllll}
\hline & \multicolumn{2}{c}{ Attitudes $^{1}$} & \multicolumn{2}{c}{ Subj. Norms ${ }^{2}$} & & PBC $^{3}$ & \multicolumn{2}{c}{ Intention $^{4}$} & \multicolumn{2}{c}{ Behaviour $^{5}$} \\
\hline Layer & Pos. & $\begin{array}{l}\text { Mean } \\
\text { (SD) }\end{array}$ & High & $\begin{array}{l}\text { Mean } \\
\text { (SD) }\end{array}$ & High & $\begin{array}{l}\text { Mean } \\
\text { (SD) }\end{array}$ & Pos. & $\begin{array}{l}\text { Mean } \\
\text { (SD) }\end{array}$ & $\begin{array}{l}\text { Pos. } \\
\text { Mean } \\
\text { (SD) }\end{array}$ \\
\hline Site & $63 \%$ & $2.3(1.0)$ & $68 \%$ & $2.5(1.1)$ & $77 \%$ & $2.1(0.9)$ & $77 \%$ & $2.0(0.9)$ & $73 \%$ & $2.1(0.9)$ \\
Structure & $76 \%$ & $1.9(0.6)$ & $71 \%$ & $2.1(0.8)$ & $53 \%$ & $2.4(0.9)$ & $63 \%$ & $2.2(0.9)$ & $79 \%$ & $2.2(0.9)$ \\
Skin & $61 \%$ & $2.1(0.9)$ & $52 \%$ & $2.1(0.9)$ & $54 \%$ & $2.5(1.0)$ & $61 \%$ & $2.5(1.0)$ & $70 \%$ & $2.2(0.9)$ \\
Services & $4 \%$ & $3.8(1.0)$ & $4 \%$ & $3.9(1.1)$ & $14 \%$ & $3.7(1.0)$ & $12 \%$ & $3.9(0.9)$ & $19 \%$ & $3.4(1.1)$ \\
Space Plan & $87 \%$ & $2.3(1.0)$ & $68 \%$ & $2.5(1.1)$ & $63 \%$ & $2.3(0.9)$ & $68 \%$ & $2.1(0.9)$ & $71 \%$ & $2.3(0.8)$ \\
Spirit of the Place & $67 \%$ & $2.2(0.9)$ & $57 \%$ & $2.5(0.9)$ & $45 \%$ & $2.9(0.8)$ & $51 \%$ & $2.5(1.0)$ & $38 \%$ & $2.5(0.9)$ \\
\hline Average & $47 \%$ & $2.4(0.9)$ & $41 \%$ & $2.7(1.0)$ & $40 \%$ & $2.8(0.9)$ & $44 \%$ & $2.6(1.0)$ & $46 \%$ & $2.4(0.9)$ \\
\hline
\end{tabular}

1 on a scale from $1-5$ where 1 is "very valuable", and 5 is "worthless"; ${ }^{2 / 4}$ on a scale from $1-5$ where 1 is "extremely likely" and 5 is "extremely unlikely"; ${ }^{3}$ on a scale from $1-5$ where 1 is "strongly agree" and 5 is "strongly disagree"; 5 on a scale from $1-5$ where 1 is " $100 \%$ " and 5 is " $\sim \% "$ ".

At the attribute level, differences emerge between the control and test groups, mainly in the more positive indicators. The relation of the building with the surroundings, the building shape, and the layout of the space plan are considered more valuable by the majority of the respondents in the control group. The control group coincides with the test group in identifying the indicators energy and heating, ventilation, and water as the most negative ones. However, despite the similar frequency of negative attitudes towards the layer "services", the control group feels less social pressure to preserve this layer than the test group and shows lower behavioural control (Table 6).

\subsection{Comparative Analysis of Intentions and Behaviours on Test and Control Groups}

Nonparametric Mann-Whitney tests were used to measure the difference in the intentions and behaviours of the test and the control group. The null hypothesis was that "the two groups have equal means on attitudes, subjective norms, perceptions of control intentions and behaviours regarding the conservation of the building attributes". The tests were performed at the broader and detailed levels. The results at the broader level of the psychological constructs are insufficient to reject the null hypothesis-the test group presents lower mean values (in a scale from 1 to 5 , where 1 is the most positive value) on subjective norms, perceived behavioural control, and intention, than the control 
group, though results are not statistically significant $(p>0.1)$. The Mann-Whitney test also suggests that attitudes are, on average, more negative in the test group. Table 7 presents the results of the Mann-Whitney test at the psychological construct level, where "T.mean rank" refers to the test group and "C.mean rank" refers to the control group, the U-value compares the differences between the two groups, and Sig. refers to the statistical significance or probability value $(p)$.

Table 6. Main positive and negative indicators in the control group.

\begin{tabular}{|c|c|c|c|c|c|c|c|c|c|c|c|}
\hline & \multirow[b]{2}{*}{ Indicator } & \multicolumn{2}{|c|}{ Attitudes $^{1}$} & \multicolumn{2}{|c|}{ Subj. Norms ${ }^{2}$} & \multicolumn{2}{|c|}{$\mathrm{PBC}^{3}$} & \multicolumn{2}{|c|}{ Intention ${ }^{4}$} & \multicolumn{2}{|c|}{ Behaviour ${ }^{5}$} \\
\hline & & Freq. & $\begin{array}{l}\text { Mean } \\
\text { (SD) }\end{array}$ & Freq. & $\begin{array}{l}\text { Mean } \\
\text { (SD) }\end{array}$ & Freq. & $\begin{array}{l}\text { Mean } \\
\text { (SD) }\end{array}$ & Freq. & $\begin{array}{l}\text { Mean } \\
\text { (SD) }\end{array}$ & Freq. & $\begin{array}{l}\text { Mean } \\
\text { (SD) }\end{array}$ \\
\hline \multirow{3}{*}{ positive } & Surroundings & $90 \%$ & $1.9(0.6)$ & $84 \%$ & $2.1(0.8)$ & $90 \%$ & $2.4(1.1)$ & $90 \%$ & $2.1(0.7)$ & $94 \%$ & $1.7(0.7)$ \\
\hline & Shape & $84 \%$ & $1.9(0.6)$ & $53 \%$ & $2.1(0.8)$ & $68 \%$ & $2.1(0.8)$ & $74 \%$ & $1.8(0.7)$ & $88 \%$ & $1.9(0.6)$ \\
\hline & Layout & $95 \%$ & $1.5(0.8)$ & $68 \%$ & $1.4(0.6)$ & $68 \%$ & $2.0(0.9)$ & $68 \%$ & $1.8(0.9)$ & $82 \%$ & $1.8(1.2)$ \\
\hline \multirow{3}{*}{ negative } & $\begin{array}{l}\text { Energy and } \\
\text { heating }\end{array}$ & $100 \%$ & $3.7(1.2)$ & $100 \%$ & $3.9(1.2)$ & $90 \%$ & $3.4(1.0)$ & $95 \%$ & $3.6(1.2)$ & $94 \%$ & $3.8(1.2)$ \\
\hline & Ventilation & $90 \%$ & $4.0(0.9)$ & $92 \%$ & $3.9(1.1)$ & $90 \%$ & $2.1(0.9)$ & $95 \%$ & $3.9(0.9)$ & $77 \%$ & $3.6(1.1)$ \\
\hline & Water & $95 \%$ & $3.5(0.9)$ & $90 \%$ & $3.8(1.1)$ & $79 \%$ & $3.1(1.1)$ & $74 \%$ & $3.3(1.0)$ & $71 \%$ & $3.4(1.4)$ \\
\hline
\end{tabular}

1 on a scale from $1-5$ where 1 is "very valuable" and 5 is "worthless"; ${ }^{2 / 4}$ on a scale from $1-5$ where 1 is "extremely likely" and 5 is "extremely unlikely"; ${ }^{3}$ on a scale from $1-5$ where 1 is "strongly agree" and 5 is "strongly disagree"; 5 on a scale from $1-5$ where 1 is " $100 \%$ " and 5 is " $\sim \% "$ ".

Table 7. Mann-Whitney test results at the psychological construct level.

\begin{tabular}{lllll}
\hline Psychological Construct & T. Mean Rank & C. Mean Rank & U & Sig. $(p)$ \\
\hline Attitude & 21.95 & 17.95 & 151 & 0.273 \\
Subjective norms & 19.75 & 20.26 & 185 & 0.888 \\
Perceived behavioural control & 19.63 & 20.39 & 182.5 & 0.833 \\
Intention & 19.02 & 21.03 & 170.5 & 0.584 \\
Behaviour & 18.61 & 17.35 & 142 & 0.716 \\
\hline
\end{tabular}

However, at the building layer and attribute levels, the analysis of frequencies shows that the test group presents more positive results than the control group in $53 \%$ of the indicators, even if not always statistically significant. Further, the Mann-Whitney tests evidence statistically significant differences between the two groups, particularly in the layers "skin" and "space plan". While in the layer "skin", the test group concentrates more positive responses, in the layer "space plan", the control group expresses stronger positive attitudes and conservation behaviours. On the one hand, attitudes towards the conservation of the skin, particularly the façade, the materials, and the detailing, are significantly more positive in the test group. Additionally, this group manifests a more robust perception of social pressure (subjective norms) to preserve the abovementioned indicators of the "skin" and more positive intentions towards the conservation of the materials. However, no significant differences were found in the self-reported behaviours towards this layer.

On the other hand, the control group (that did not use the building passport) shows more positive attitudes towards the conservation of the space plan, both of the layout and the interior-exterior relationships. Thus, even though no significant differences were found in the intentions towards the conservation of the space plan, the control group self-reports to have conserved more of the space plan layout. Table 8 summarises the attributes in which statistically significant differences were found between the control and the test group. 
Table 8. Significant differences at the building layer and indicator level.

\begin{tabular}{|c|c|c|c|c|c|}
\hline Psychological Construct & Layer. Indicator & T. Mean Rank & C. Mean Rank & $\mathbf{U}$ & Sig. $(p)$ \\
\hline \multirow[t]{7}{*}{ Attitudes } & Skin & 15.83 & 24.39 & 106.5 & 0.018 * \\
\hline & Conservation of the façade & 15.65 & 24.58 & 103 & $0.008 * *$ \\
\hline & Conservation of the materials & 16.80 & 23.37 & 126 & $0.042 *$ \\
\hline & Conservation of technique and detailing & 16.52 & 23.66 & 120.5 & 0.039 * \\
\hline & Space Plan & 25.23 & 14.50 & 85.5 & $0.003 * *$ \\
\hline & Conservation of the layout & 25.75 & 13.95 & 75 & $0.001 * *$ \\
\hline & Conservation of the relation with the exterior & 23.43 & 16.39 & 121.5 & $0.042 *$ \\
\hline \multirow[t]{12}{*}{ Subj. Norm } & Site & 23.0 & 16.84 & 130 & 0.088 \\
\hline & Conservation of the relation with climate & 22.2 & 17.68 & 146 & 0.201 \\
\hline & Skin & 15.93 & 24.29 & 108.5 & 0.021 \\
\hline & Conservation of the façade & 15.60 & 24.63 & 102 & $0.007^{* *}$ \\
\hline & Conservation of the roof & 16.93 & 23.24 & 128.5 & 0.076 \\
\hline & Conservation of the materials & 17.18 & 22.97 & 133.5 & 0.085 \\
\hline & Conservation of technique and detailing & 15.73 & 24.50 & 104.5 & $0.010 * *$ \\
\hline & Services & 17.75 & 22.37 & 145 & 0.194 \\
\hline & Conservation of energy and heating system & 17.60 & 22.53 & 142 & 0.150 \\
\hline & Conservation of ventilation system & 17.58 & 22.55 & 141.5 & 0.147 \\
\hline & Space Plan & 22.73 & 17.13 & 135.5 & 0.118 \\
\hline & Conservation of the layout & 22.68 & 17.18 & 136.5 & 0.120 \\
\hline \multirow[t]{12}{*}{ PBC } & Site & 23.98 & 15.82 & 110.5 & $0.023 *$ \\
\hline & Conservation of the relation with climate & 22.38 & 17.50 & 142.5 & 0.149 \\
\hline & Conservation of the relation with topography & 23.38 & 16.45 & 122.5 & $0.044^{*}$ \\
\hline & Skin & 17.75 & 22.37 & 145 & 0.204 \\
\hline & Conservation of the materials & 16.68 & 23.50 & 123.5 & $0.045 *$ \\
\hline & Conservation of technique and detailing & 17.40 & 22.74 & 138 & 0.123 \\
\hline & Conservation of building shape & 17.70 & 22.42 & 144 & 0.172 \\
\hline & Services & 16.85 & 23.32 & 127 & 0.071 \\
\hline & Conservation of energy and heating system & 17.48 & 22.66 & 139.5 & 0.140 \\
\hline & Conservation of ventilation system & 16.48 & 23.71 & 119.5 & $0.040 *$ \\
\hline & Space Plan & 22.38 & 17.50 & 142.5 & 0.172 \\
\hline & Conservation of the layout & 22.28 & 17.61 & 144.5 & 0.181 \\
\hline \multirow[t]{11}{*}{ Intention } & Site & 23.18 & 16.66 & 126.5 & 0.071 \\
\hline & Conservation of the relation with climate & 22.78 & 17.08 & 134.5 & 0.089 \\
\hline & Structure & 18.38 & 21.71 & 157.5 & 0.346 \\
\hline & Conservation of the structural materials & 17.48 & 22.66 & 139.5 & 0.127 \\
\hline & Skin & 16.58 & 23.61 & 121.5 & 0.053 \\
\hline & Conservation of the façade & 17.80 & 22.32 & 146 & 0.171 \\
\hline & Conservation of the materials & 16.73 & 23.45 & 124.5 & $0.048^{*}$ \\
\hline & Services & 17.98 & 22.13 & 149.5 & 0.246 \\
\hline & $\begin{array}{l}\text { Conservation of the energy and heating } \\
\text { system }\end{array}$ & 17.63 & 22.50 & 142.5 & 0.163 \\
\hline & Space Plan & 22.60 & 17.26 & 138 & 0.136 \\
\hline & Conservation of the layout & 17.11 & 22.75 & 135 & 0.102 \\
\hline \multirow[t]{4}{*}{ Behaviour } & Skin & 16.28 & 19.82 & 122 & 0.303 \\
\hline & Conservation of the façade & 15.83 & 20.29 & 114 & 0.171 \\
\hline & Space Plan & 18.92 & 17.03 & 136.5 & 0.578 \\
\hline & Conservation of the layout & 13.32 & 22.42 & 73.5 & $0.004^{* *}$ \\
\hline
\end{tabular}

*. Correlation is significant at the 0.05 level (2-tailed). ${ }^{* *}$. Correlation is significant at the 0.01 level (2-tailed).

\subsection{Measuring the Intention-Behaviour Gap in the Test and Control Groups}

To further understand the differences identified through the Mann-Whitney tests, bivariate correlation analysis was performed to observe differences in the correlation between the psychological constructs in the test and control groups. This analysis supports the correlations predicted by the theoretical model [19,20,43,49-51], demonstrating the role of attitudes, subjective norms, and perceived behavioural control in shaping conservation intentions. However, while the theoretical model strongly supports the prediction of intention, the same does not happen with the prediction of behaviour, which is not statistically 
significant (see Table 9). Although in the scope of this research, conservation behaviours are not directly correlated with expressed intentions, the results show a positive correlation between attitudes and behaviours, both in the test $(p=0.039)$ and in the control group $(p=0.069)$.

Table 9. Pearson correlations among analysed psychological constructs.

\begin{tabular}{|c|c|c|c|c|c|}
\hline & & Intention & & Behavic & \\
\hline & & Test & Control & Test & Control \\
\hline \multirow[t]{3}{*}{ Intention } & Pearson Correlation (r) & 1 & 1 & 0.370 & 0.332 \\
\hline & Sig. (2-tailed) $(p)$ & & & 0.130 & 0.193 \\
\hline & $\mathrm{N}$ & 20 & 19 & 18 & 17 \\
\hline \multirow[t]{3}{*}{ Behaviour } & Pearson Correlation (r) & 0.370 & 0.332 & 1 & 1 \\
\hline & Sig. (2-tailed) $(p)$ & 0.130 & 0.193 & & \\
\hline & $\mathrm{N}$ & 18 & 17 & 18 & 17 \\
\hline \multirow[t]{3}{*}{ Attitudes } & Pearson Correlation (r) & $0.880 * *$ & $0.653 * *$ & $0.490 *$ & 0.451 \\
\hline & Sig. (2-tailed) $(p)$ & 0.000 & 0.002 & 0.039 & 0.069 \\
\hline & $\mathrm{N}$ & 20 & 19 & 18 & 17 \\
\hline \multirow[t]{3}{*}{ Subj. norms } & Pearson Correlation (r) & $0.825^{* *}$ & $0.825^{* *}$ & $0.576^{*}$ & 0.473 \\
\hline & Sig. (2-tailed) $(p)$ & 0.000 & 0.000 & 0.012 & 0.055 \\
\hline & $\mathrm{N}$ & 20 & 19 & 18 & 17 \\
\hline \multirow[t]{3}{*}{ PBC } & Pearson Correlation (r) & $0.554 *$ & $0.664^{* *}$ & 0.381 & 0.088 \\
\hline & Sig. (2-tailed) $(p)$ & 0.011 & 0.002 & 0.119 & 0.736 \\
\hline & $\mathrm{N}$ & 20 & 19 & 18 & 17 \\
\hline
\end{tabular}

Some differences emerge between the two groups, namely regarding the strength of moderating beliefs in the formation of intentions. In the test group, attitudes have a stronger positive correlation with intentions $(\mathrm{r}=0.880, p<0.001)$ than in the control group $(r=0.653, p<0.001)$, evidencing that an increase in positive attitudes increases positive intentions after implementing the passport. In the test group, subjective norms and perceived behavioural control present positive correlations with intentions, too, but to a lesser degree than attitudes. In the control group, however, subjective norms $(\mathrm{r}=0.825$, $p<0.001)$ and perceived behavioural control $(\mathrm{r}=0.664, p=0.002)$ are stronger predictors of intention than attitudes $(r=0.639, p<0.001)$. Interestingly, subjective norms present the same correlation with intentions in the test and the control groups, suggesting that tutors' expectations have an important moderation effect on personal evaluations.

Since no correlation was found between intentions and behaviours, the effect of applying the building passport was analysed by comparing the most determinant variables for conservation intentions through single linear regression. Table 10 presents the results of the single linear regressions, on which " $\mathrm{B}$ " stands for beta coefficient (the degree of change in the outcome variable for every unit of change in the predictor variable), " $R^{2}$ " refers to R-squared (goodness-of-fit measure for the model), and "Sig." refers to the statistical significance, through the probability value $(p)$. 
Table 10. Single linear regression between independent variables and "conservation intention".

\begin{tabular}{|c|c|c|c|c|c|c|c|}
\hline & & \multicolumn{3}{|c|}{ Control } & \multicolumn{3}{|c|}{ Test } \\
\hline & & B & Sig. $(p)$ & $\mathbf{R}^{2}$ & B & Sig. $(p)$ & $\mathbf{R}^{2}$ \\
\hline \multirow{4}{*}{ Site } & Attitudes & $0.274 *$ & 0.030 & 0.247 & 0.273 & 0.075 & 0.166 \\
\hline & Subj. Norms & $0.290 *$ & 0.037 & 0.231 & $0.449 * *$ & 0.000 & 0.534 \\
\hline & PBC & 0.324 & 0.120 & 0.136 & 0.063 & 0.671 & 0.010 \\
\hline & Attitudes & 0.245 & 0.126 & 0.132 & 0.069 & 0.773 & 0.005 \\
\hline \multirow[t]{3}{*}{ Structure } & Subj. Norms & $0.430^{* *}$ & 0.002 & 0.447 & 0.192 & 0.246 & 0.074 \\
\hline & PBC & $0.381^{* *}$ & 0.003 & 0.405 & -0.021 & 0.852 & 0.002 \\
\hline & Attitudes & $0.605^{* *}$ & 0.001 & 0.511 & 0.299 & 0.116 & 0.132 \\
\hline \multirow[t]{3}{*}{ Skin } & Subj. Norms & $0.540^{* *}$ & 0.000 & 0.680 & 0.229 & 0.165 & 0.104 \\
\hline & PBC & 0.346 * & 0.024 & 0.264 & 0.281 & 0.058 & 0.185 \\
\hline & Attitudes & 0.009 & 0.955 & 0.000 & $0.267 *$ & 0.013 & 0.294 \\
\hline \multirow[t]{3}{*}{ Services } & Subj. Norms & 0.116 & 0.480 & 0.030 & 0.218 & 0.012 & 0.305 \\
\hline & PBC & -0.161 & 0.203 & 0.093 & $0.404^{* *}$ & 0.000 & 0.582 \\
\hline & Attitudes & 0.151 & 0.425 & 0.038 & $0.376^{* *}$ & 0.000 & 0.648 \\
\hline \multirow[t]{3}{*}{ Space Plan } & Subj. Norms & 0.088 & 0.464 & 0.032 & $0.308^{* *}$ & 0.000 & 0.536 \\
\hline & PBC & $0.382^{* *}$ & 0.003 & 0.416 & $0.250 *$ & 0.034 & 0.226 \\
\hline & Attitudes & $0.377^{*}$ & 0.010 & 0.334 & 0.160 & 0.162 & 0.111 \\
\hline \multirow[t]{2}{*}{ Spirit of Place } & Subj. Norms & $0.455^{* *}$ & 0.001 & 0.495 & $0.288 *$ & 0.024 & 0.265 \\
\hline & PBC & $0.588^{* *}$ & 0.004 & 0.395 & $0.288 *$ & 0.015 & 0.301 \\
\hline
\end{tabular}

The results showed a significant relationship between the attitudes towards the "services" $\left(R^{2}=0.294 ; p=0.013\right)$ and the "space plan" $\left(R^{2}=0.648, p<0.001\right)$ and overall conservation intentions in the test group. Subjective norms also have a significant contribution in this group, moderating the conservation intentions in the layer "services" $\left(R^{2}=0.582 ; p<0.001\right)$. With an $R^{2}$ value of 0.648 , the attitudes towards the "space plan" have the most substantial effect on the overall expressed conservation intentions. In the opposite direction, the structure layer is the least significant in predicting the conservation intentions of the participants who used the building passport, followed by the layer "skin". This result suggests that general conservation intentions do not reflect the high attitudes towards structure and skin. However, they tend to be moderated by the lower valued layers, such as the services and the space plan.

Almost symmetrically, in the control group, the attitudes towards the layer "skin" have the most significant correlation with conservation intentions $\left(R^{2}=0.511 ; p=0.001\right)$, while the attitudes towards the "services" $\left(R^{2}=0.000 ; p=0.955\right)$ and the "space plan" $\left(R^{2}=0.038 ; p=0.425\right)$ have the lowest one.

Considering the single linear regression results, multiple regression with backwards elimination was performed to find out the models that better explain the conservation intentions in the test and the control groups. The results, presented in Table 11, confirm that expressed intentions on the control group tend to be normative controlled. The model of intentions in the control group, explaining until $92.5 \%$ of the variance on intentions $\left(R^{2}=0.925\right)$, suggests that the most positive intentions towards conservation are found in the students with higher perceptions of social pressure towards the conservation of the site, the skin, the services, and the spirit of place. It also suggests that highly positive attitudes towards the façade do not reflect overall positive conservation intentions.

In the test group, the results of the multiple regression suggest attitudinally controlled intentions (Table 11). In this case, stronger conservation intentions were found in students who report positive attitudes towards the services, space, and spirit, but, again, not necessarily towards the conservation of the façade. The norms towards the structure and the spirit of place present a negative correlation with intention, meaning that the higher the perception of social pressure to conserve, the lower the conservation intentions. At the same time, the attitudes towards the conservation of the spirit of place contributed significantly to the model $(B=0.298, p<0.001)$, while the attitudes towards the conservation of the skin did not $(\mathrm{B}=-0.095, p=0.094)$. 
Table 11. Multiple regression models on "conservation intentions" and "conservation behaviours".

\begin{tabular}{|c|c|c|c|c|c|}
\hline & & \multicolumn{2}{|c|}{ Control } & \multicolumn{2}{|c|}{ Test } \\
\hline & & B Intention & B Behaviour & B Intention & B Behaviour \\
\hline & (constant) & 0.068 & 1.895 & 0.790 & 0.181 \\
\hline \multirow{6}{*}{ Attitudes } & Site & - & - & - & 0.485 \\
\hline & Skin & -0.328 & - & -0.095 & 0.270 \\
\hline & Structure & - & - & - & - \\
\hline & Services & - & -0.215 & 0.130 & -0.431 \\
\hline & Space & - & - & 0.253 & 0.306 \\
\hline & $\begin{array}{l}\text { Spirit of } \\
\text { Place }\end{array}$ & - & 0.254 & 0.298 & 0.384 \\
\hline \multirow{5}{*}{ Subj. Norms } & Site & 0.161 & - & 0.185 & - \\
\hline & Skin & 0.341 & - & - & - \\
\hline & Structure & - & - & -0.191 & 0.719 \\
\hline & Services & 0.158 & - & - & 0.292 \\
\hline & Space & - & 0.388 & 0.193 & - \\
\hline \multirow{7}{*}{ PBC } & $\begin{array}{l}\text { Spirit of } \\
\text { Place }\end{array}$ & 0.316 & - & -0.212 & -0.801 \\
\hline & Site & - & - & - & - \\
\hline & Skin & - & - & 0.160 & - \\
\hline & Structure & 0.244 & - & 0.102 & - \\
\hline & Services & - & - & - & - \\
\hline & Space & - & - & -0.189 & - \\
\hline & $\begin{array}{l}\text { Spirit of } \\
\text { Place }\end{array}$ & - & - & - & - \\
\hline
\end{tabular}

The results show that both intentions and behaviours are strongly led by normative and attitudinal beliefs, with perceived behavioural control having a minor influence on conservation decisions in the case study. While intentions do not significantly correlate with reported behaviours, the Pearson correlation showed relevant correlations of behaviour with attitudes and subjective norms that were further investigated through multiple linear regression to identify the main differences between expressed intentions and reported behaviours. In the analysis of behaviour, attitudes overtake norms in the control group, with a significant contribution of the attitudes towards the services $(p=0.083)$ and the spirit of place $(p=0.031)$. Together with the norms towards the conservation of the space $(p<0.001)$, the model explains around $68 \%$ of the variance in behaviour $\left(R^{2}=0.675\right)$ in the control group (Table 11).

Regarding the conservation behaviours in the control group, the perception of the norms towards the space and the attitudes towards the spirit of the place highly influence positive conservation behaviours. Negative attitudes towards the services, on the contrary, do not translate into negative conservation behaviours.

In the test group, attitudes remain the most influential psychological construct to predict conservation behaviours. Attitudes towards the conservation of the services layer have a negative correlation with behaviour $(B=-0.431, p=0.004)$, suggesting that even if participants show a negative attitude than can end up preserving this layer due to intervening factors, the fact that norms towards this layer have a significant positive correlation ( $\mathrm{B}=0.292, p=0.010$ ) with behaviour may help to explain this difference. Compared with the model explaining conservation intentions in the test group, attitudes towards the skin change to a positive correlation $(B=0.270, p=0.052)$, while the norms towards the spirit have a significantly more negative influence on conservation behaviours $(\mathrm{B}=-0.801, p=0.006)$ than in conservation intentions.

The predictive model for conservation behaviour of the test group $\left(R^{2}=0.937\right)$ suggests that more positive conservation behaviours happen with students who have positive attitudes towards the conservation of site, space, and spirit, despite negative attitudes towards the conservation of the services (Table 11). However, the higher subjective norms 
towards the conservation of the spirit do not translate into general positive conservation behaviours. As suggested by the descriptive statistics, this may happen because of the moderation effect of the low perceived behavioural control.

\subsection{Correlations between Behaviour and the Building Passport}

The regression analysis of intentions and behaviours suggests differences between the test and the control groups, with the models of the test group expressing more complex decision processes, with more factors affecting the reported conservation behaviours. To analyse the causal effect of the passport and the differences found between the test and control groups (Table 10), single linear regression was applied for each indicator of the building passport. The indicators for which significant relationships were found are presented in Figure 2, including the average sustainability assessment from the test group, the directionality of the relation (positive or negative), and if there were significant differences with the control group in the Mann-Whitney test.

The results show significant correlations, mainly between the passport and the attitudes ( $22 \%$ of the indicators) and subjective norms $(25 \%)$. In addition, perceived behavioural control (17\%), intentions and behaviours (both $14 \%$ of the indicators) seem to be affected by the building passport, but to a lesser extent. While some relations are positive-with positive assessments increasing the likelihood of positive conservation behaviours-some relations are negative, suggesting that despite negative assessments, participants can still engage in positive conservation behaviours and vice versa.

In general, attitudes present a positive correlation with the passport. Interestingly, these correlations emerge dominantly in indicators with lower assessment ratings $(C, D$, or B-), such as "sufficient thermal insulation", "windows avoid thermal losses", or "presence of energy autonomy strategies". This suggests that the passport has a role in reinforcing pre-existing negative beliefs about specific building attributes. Significant correlations, however, also emerge in the most positive indicators, rated with A, such as "presence of transitional spaces" or structures that are "simple to build and maintain".

Moreover, the correlation with subjective norms is mostly positive, with higher sustainability assessment relating to higher perceptions of social pressure to conserve the building. However, as happened with the attitudes, this correlation emerges more clearly when assessments are low (C, D), indicating that the building passport might justify decisions not to conserve the services and the envelope attributes related to energy needs (such as openings, façade, and roof).

In analysing the perceived behavioural control, an essential number of negative correlations emerge in the layer "structure". This result suggests that despite the positive contributions for sustainability (ratings A and B), participants do not perceive behavioural control over the conservation of this layer, influencing their intention to preserve it. Together with the negative correlations found between the sustainability assessment and attitudes and subjective norms in this layer, the model explains the negative correlation between the intention to conserve the structure and the positive assessments in the building passport.

The assessment of the indicator "positive impact on biodiversity" affects attitudes, subjective norms, and intentions towards the site's conservation. The assessment on the indicator "energy needs", in the skin layer, and on the indicators related with water and energy and heating, in the services layer, consistently affect attitudes, norms, perception of control and intentions, shaping results significantly different from the control group, according to the Mann-Whitney test. The fact that the Mann-Whitney tests show significant differences in indicators on which no direct correlation with the passport was found suggests an indirect multi-effect of the sustainability assessment-for instance, while the assessment of the "relation of the building with climate" affects attitudes towards the conservation of this attribute, the most significant differences between the test and the control group emerge on the subjective norms and intentions. Thus, a possible interpretation is 
that the sustainability assessment may indirectly affect participants' perceptions of norms and expressed intentions.
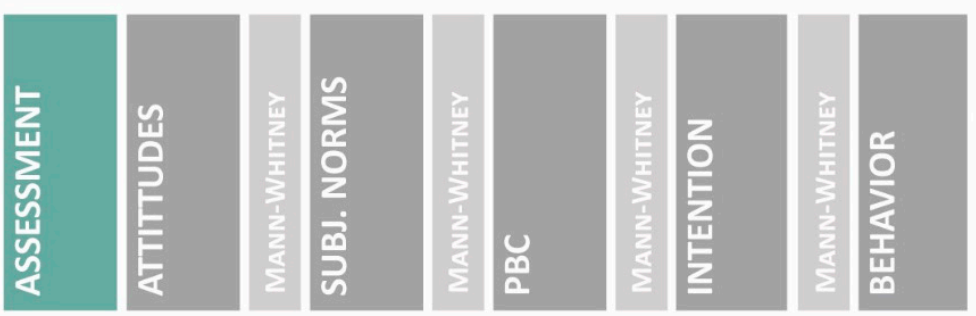

\begin{tabular}{|l|}
\hline SITE \\
\hline SOIL \& TOPOGRAPHY \\
\hline CLIMATE \\
\hline SURROUNDINGS \\
\hline
\end{tabular}

B-

B-

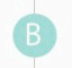

(B)

\section{SKIN}

\section{SHAPE}

\begin{tabular}{|l|}
\hline DETAILING \\
\hline MATERIALS \\
\hline ENERGY \\
\hline STRUCTURE \\
\hline
\end{tabular}

\section{STRUCTURE}

\begin{tabular}{|l|}
\hline SYSTEM \\
\hline DETAILING \\
\hline MATERIALS \\
\hline
\end{tabular}

\section{SERVICES}

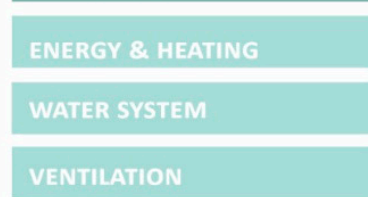

\section{SPACE PLAN}

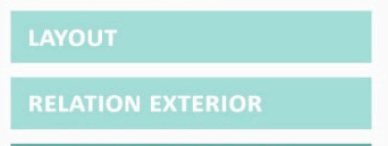

\section{SPIRIT OF PLACE}

\begin{tabular}{|l|}
\hline COMMUNITY \\
\hline PLACE-BASED \\
\hline OVERALL \\
\hline
\end{tabular}

\section{B-}

(B)
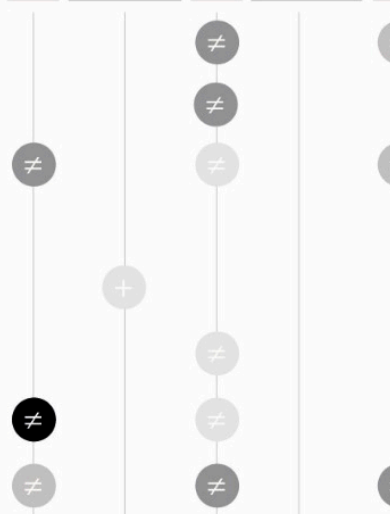

(十)
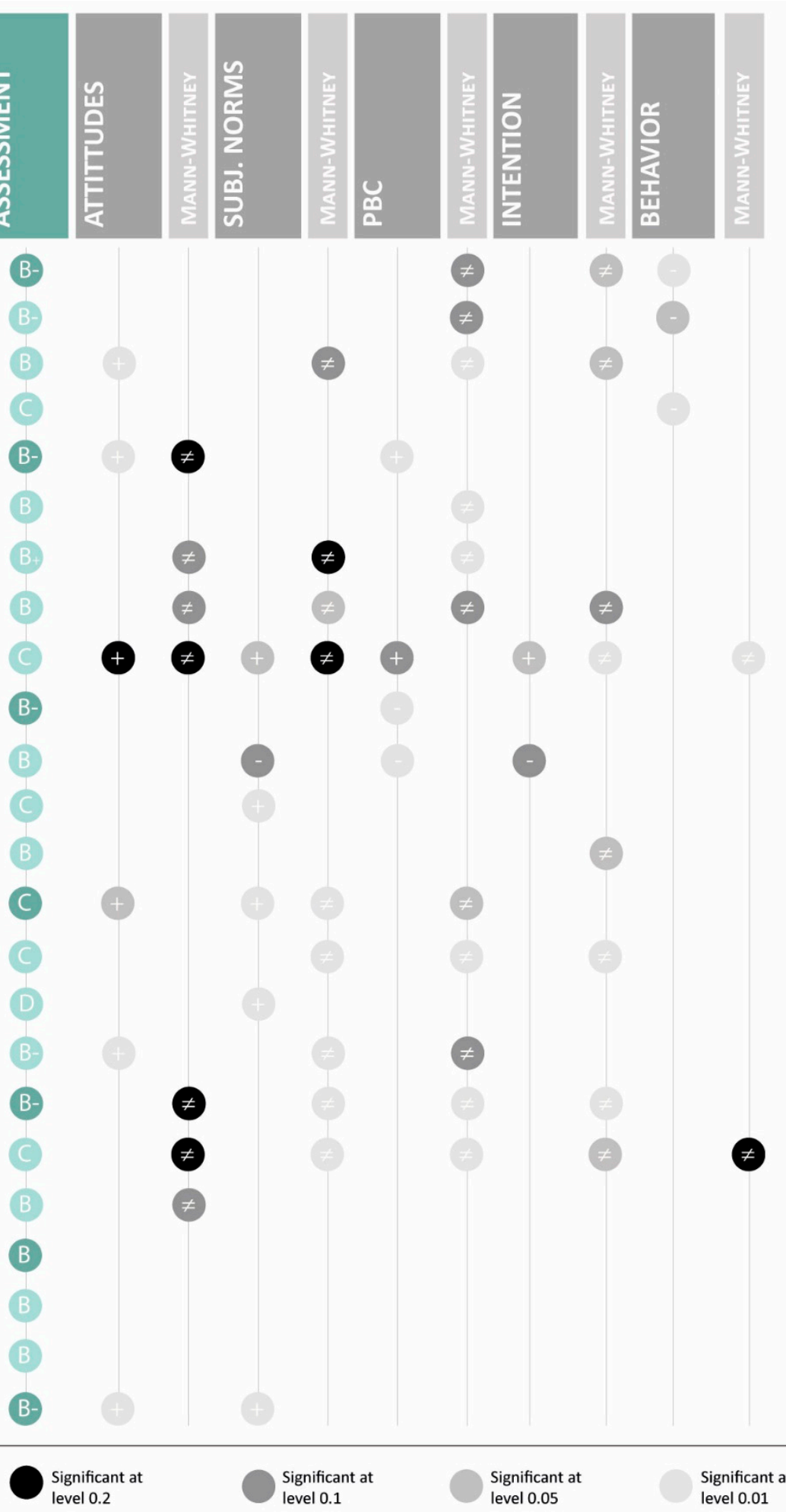

Figure 2. Correlations between the building passport assessment of the test group and behaviour. 


\subsection{Reasons for the Intention-Behaviour Gap}

When asked to rank the values that may affect their intentions to conserve building attributes, the participants in the test group (that used the building passport) identify historic and aesthetic values within the same level of importance, followed by the age of the attribute. When dealing with the conservation of the building's skin, aesthetical values have priority. Still, historic values have more relevance in decisions related to the spirit of the place and the relation with the site. The economic value is considered a priority when dealing with the conservation of the services. Ecological values appear in the middle of the ranking ( 4 out of 7 ) and never reach the top three criteria affecting decisions in the different building layers, as shown in Table 12.

Table 12. Ranking of the values affecting the conservation of the building layers.

\begin{tabular}{lccccccc}
\hline & Site & Skin & Structure & Services & Space & Spirit of Place & Overall \\
\hline Aesthetic & 2 & 1 & 1 & 3 & 2 & 4 & $1^{*}$ \\
Historical & 1 & 2 & 2 & 5 & 1 & 2 & $1^{*}$ \\
Age & 3 & 3 & 3 & 4 & 4 & 3 & 2 \\
Social & 4 & 5 & 6 & 7 & 3 & 1 & 3 \\
Ecological & 5 & 4 & 5 & 2 & 6 & 5 & 4 \\
Economic & 6 & 6 & 4 & 1 & 5 & 6 & 5 \\
Scientific & 7 & 7 & 7 & 6 & 7 & 7 & 6 \\
Political & 8 & 8 & 8 & 8 & 8 & 8 & 7 \\
${ }^{*}$ ex aequo. & & & & & & &
\end{tabular}

The analysis of the reasons pointed out by respondents for the gap between expressed intentions and self-reported behaviours towards conservation of building elements does evidence some differences and commonalities in the respondents that previously used the building passport from the ones who did not. In both groups, the new program requirements are pointed out as the main reason impeding conservation $35 \%$ in the control group and $44 \%$ in the test group), followed by decisions related to design concepts ( $25 \%$ in the control group and $22 \%$ in the test group). Some respondents point out the existing elements as obsolete and restrictive to the new design and spatial quality. Sustainability issues related to energy demands, insulation, and comfort are identified by $15 \%$ of respondents of the control group as reasons not to conserve built heritage attributes. Still, only $5 \%$ of respondents in the test group specify this reason.

\section{Discussion}

\subsection{Contributions to Increase Sustainable Conservation}

By allowing the identification of the least sustainable layers, the building passport supports users in decisions on which attributes to conserve and which attributes are less valuable from a sustainability perspective. As such, the building passport does not necessarily contribute to higher overall conservation rates but to more targeted and informed decisions. According to respondents' attitudes, the services layer, pointed out in the building passport as the least sustainable, also appears as the least valuable. After applying for the building passport, the test group reports higher perceived behavioural control over the conservation of the services and higher intention and behaviours than the control group, but the combination of low value and low contribution to sustainability makes this layer the least conserved. This suggests a positive contribution of the building passport in the identification of opportunities to redesign. The spirit layer was assessed in the building passport as having a positive contribution to sustainability that should be conserved. After applying for the passport, the test group shows, in general, more positive conservation intentions and higher conservation behaviours than the control group (Tables 5-8). Nevertheless, confirming the results of previous studies [39], the spirit of the place presents the lower levels of perceived behavioural control that need to be tackled to ensure the effective conservation of this attribute. 
The Mann-Whitney analysis allowed us to identify with further detail for which building attributes significant differences emerge due to the application of the building passport. As suggested by the descriptive statistics, significant differences emerge in the layers skin, space plan, services, and site. The test group shows more positive attitudes, higher subjective norms, and more positive intentions towards conserving the skin materials and detailing. The same indicators were highlighted as more sustainable in the skin layer of the building passport. As already happened in a previous study [39], the skin layer is considered one of the most important ones in building conservation. It consistently presents positive attitudes towards its conservation, translating into positive intentions and positive behaviours. However, the results show that the overall conservation intentions do not reflect extreme peaks and tend to be moderated by other factors. In essence, a respondent with consistent, lower average attitudes is more likely to engage in more positive conservation behaviours than a respondent with particular, extremely high attitudes towards a specific building attribute.

While in the building passport, the "relation with the exterior" in the space plan layer is clearly assessed as positive; the same does not happen with the indicator "layout", with a lower result in the assessment. That may explain why the control group presents significantly more positive attitudes towards the conservation of the space plan and reports significantly more positive conservation behaviours of the layout, with subjective norms having a significant role in the conservation decision. These differences found in the space plan layer, in particular, of the indicator layout, point out some risks of relying exclusively on a sustainability assessment tool to inform conservation decisions. The fact of the positive correlations of subjective norms with the passport showing a predominant correlation with the most negative assessments strengthens the hypothesis that users of the building passport may feel less social pressure to preserve the less sustainable attributes and rely on this tool as a justification to destroy them, disregarding other possible values (aesthetical, historical, or others). Complementary tools that allow one to analyse the state of conservation $[49,52,53]$ and assess cultural significance $[4,50]$ must be used to ensure a holistic understanding of the building.

The results show the validity of the theoretical model, the Theory of Planned Behaviour [18-20], to "gain insight into the important considerations that guide people's decisions and actions" [42] in the context of built heritage conservation. Strong correlations emerge between attitudes, subjective norms, perceived behavioural control, and intentions in both the test and control groups. Attitudes also appear as strongly correlated with behaviours, as already suggested by Gonçalves et al. [39]—attitudes matter for heritage conservation. While intentions in the test group are dominantly motivated by attitudes, in the control group they are normatively controlled, influenced by perceptions of social pressure by tutors and peers. This suggests that the building passport can contribute to identifying opportunities for the redesign. Previous studies in the field of psychology [51] determined that attitudinally controlled intentions have a greater likelihood of performance than normatively controlled intentions since they are self-chosen and not externally imposed. In the present research, the results suggest a positive contribution of the building passport to reinforce attitudes and personal motivations, raising confidence towards the conservation of building attributes and strengthening the intention-behaviour relationship.

As already identified in previous studies addressing designers' decision behaviours [37,38], subjective norms have a limited role as a predictor of behaviour, highlighting the importance of internal motivations over external pressure. However, while the results of Lee et al. [37] and Li et al. [38] with practitioners identify PBC as the stronger predictor of behaviour, the current results demonstrate that with design students, PBC has a negligible role. On one hand, this confirms the premise of this study-in an educational context, students have fewer constraints and more autonomy in design decisions. On the other hand, it evidences the importance of applying this methodology with design practitioners, to verify the influence of other factors such as cooperation with stakeholders, costs, time, or opportunity [13], in the final design decisions. 
This research targeted a primary belief found among students [39] and practitioners [13-16] that heritage buildings cannot be thoroughly conserved because they are not sustainable. The results show that by being exposed to new information and by being actively engaged in the persuasion process, through the sustainability assessment, participants show different attitudes, intentions, and behaviours towards certain building attributes compared to the respondents in the control group. However, the changes seem to be insufficient to produce a significant change in the total belief indices and, above all, in the self-reported behaviours. While in earlier research, a correlation was found between intention and behaviour [39], in the current study, the lack of statistically significant correlations makes direct comparisons unviable to determine the influence of the building passport in the increase in implementation of intentions. Three reasons may contribute to explain these results: the quality and stability of intentions, as defined by Sheeran [54]; the primary beliefs targeted, according to Fishbein and Ajzen [42]; and the stage of behavioural change, according to Prochascka et al. [55].

According to Sheeran and Webb [54], directionality and intensity are not enough to measure behavioural intentions since they also differ in their quality. Among the factors affecting intentions implementation, Sheeran $[51,54]$ identifies temporal stability, certainty, and accessibility. These aspects are related to how confident the respondents are in the expressed intention and how likely is it to change over time, either because it was forgotten or because new information changed the original decision. The fact that some participants in the study point out "changes of mind" (Section 3.5) as a primary reason to not have behaved as intended suggests that the expressed intentions were not stable enough to ensure correlations with the self-reported behaviours, also motivated by a particularly unstable context, during the COVID-19 pandemic. Considering the properties of intentions defined by Sheeran and Webb [54], the building passport might also be used as a monitoring tool, ensuring that users develop their design process without losing track of their previous sustainability assessment and expressed intentions.

According to Fishbein and Ajzen [42], for an intervention to be successful in changing intentions, it must target primary beliefs: "the beliefs that provide the foundation for the behaviour of interest". While building sustainability is often pointed out as one reason not to conserve certain building attributes, this is not the only belief hindering heritage conservation and might not be the most important one. Aesthetic reasons, related to the limitations to creativity and innovation imposed by the necessity of dealing with preexisting attributes and the adaptation to program requirements, are more often pointed out by participants, both in the test and in the control group. This may explain why, despite some differences between the test and the control group regarding attitudes, subjective norms, and intentions, no significant changes were found in the overall self-reported behaviours. Using the TPB, other mechanisms can be tested targeting different beliefs of designers involved in heritage conservation processes.

The transtheoretical model of change of Prochaska et al. [55] suggests that behavioural change involves a sequence of five different stages, from no intention to perform a behaviour to a consistent behavioural performance. This model demonstrates that "behaviour change is not an all-or-none phenomenon" [42] since it involves a series of stages and different strategies to move people from one stage to another. Thus, while the building passport seems to be an effective tool to introduce new beliefs regarding built heritage sustainability, contributing to more positive intentions, further steps must be taken to support designers to act on their intentions.

\subsection{Limitations and Future Research}

This paper presents the results of a pilot study applying the theory of planned behaviour to heritage conservation and, in particular, to analyse design decision behaviours. This is a recent innovative field, not previously explored [18]. Because of its novelty, this study is not exempt from limitations that should be further explored in future research. Firstly, a small sample was used due to the COVID-19 limitations, with only 20 participants 
in both the control and the test groups. This aspect may limit the accuracy of the results and, as they showed, restrict the possibilities of finding statistically significant results. Future research shall validate these results by extending the sample population and exploring the relations between the variables affecting conservation behaviours with more accuracy. Secondly, the sample population is limited to architecture master students and does not fully represent the reality of professional practice. While this was a deliberate decision in the study design to isolate internal factors affecting decision-making [45], it is essential to explore further how actual behavioural control, affected by real conditions, legislation, and interaction with other stakeholders, affects the correlation between intentions and behaviours towards sustainable conservation. With this purpose, the distribution and application of the questionnaire among professional organisations in the heritage conservation field may elicit how the behaviour of different stakeholders is related to intentions, and affected by perceived behavioural control, subjective norms, and attitudes.

\section{Conclusions}

This paper aimed to investigate the effect of a building passport for sustainable conservation on designers' intentions and behaviours towards built heritage conservation. The TPB allowed us to verify the efficacy of an intervention targeting the belief of designers that "compatibility with sustainability" is a barrier to built heritage conservation. The use of the BPSC influences beliefs towards certain building attributes, but current results do not substantiate significant changes in the overall conservation behaviours. By evidencing which building attributes have a lower contribution to sustainability, the BPSC allows for establishing intervention priorities. Thus, conservation behaviours are not necessarily more positive, even if more informed and targeted. Nevertheless, evidence suggests that this tool positively contributes to reinforcing existing attitudinal beliefs and confirms that attitudes matter for sustainable heritage conservation. This paper also allowed us to identify aspects that may be improved in future research since behavioural change towards sustainable conservation happens one step at a time.

Supplementary Materials: The following are available online at https:/ / www.mdpi.com/article/10 $.3390 /$ su13158280/s1.

Author Contributions: All authors contributed to the conception and design of the research work. J.d.S.G. collected the data, performed the analysis, and draft the article. R.M., J.D.S., and A.R.P.R. revised the manuscript critically for important intellectual content and approved the version of the manuscript to be published. All authors have read and agreed to the published version of the manuscript.

Funding: This research was funded by Foundation for Science and Technology (FCT), grant number PD/BD/127853/2016. The APC was funded by TU Delft Library.

Institutional Review Board Statement: Ethical review and approval were waived due to the minimal risk of the study. The study did not involve participants who are particularly vulnerable or unable to give informed consent or in a subordinate position to the investigators. Participants were informed of the scope of the study and voluntarily gave their consent to participate, in the opening of the questionnaire. No personal sensitive data was collected, and no harm or negative consequences were caused to participants in the scope of this study. The questionnaire was distributed online via anonymous link. Results were analyzed collectively for statistical purposes, and not individual answers can be connected to the respondents.

Informed Consent Statement: Informed consent was obtained from all subjects involved in the study.

Data Availability Statement: The data presented in this study are available on request from the corresponding author. The data are not publicly available due to privacy.

Acknowledgments: The authors would like to acknowledge the support granted by the Portuguese Foundation for Science and Technology (FCT), in the scope of the Doctoral Program EcoConstruction and Rehabilitation (EcoCoRe), to the Ph.D. scholarship of the first author with the 
reference PD/BD/127853/2016, and the support of ISISE, from the UMinho, CERIS, from IST-UL, and of the Heritage \& Architecture section, from AE-T-BK at TU Delft.

Conflicts of Interest: The authors declare no conflict of interest.

\section{References}

1. United Nations. Transforming Our World: The 2030 Agenda for Sustainable Development; Uniter Nations: Geneva, Switzerland, 2015.

2. UNESCO. Recommendation on the Historic Urban Landscape; UNESCO: Paris, France, 2011.

3. Roders, A.P.; Post, J.; Erkelens, P.A. Re-Architecture: Reality or Utopia? In CIB World Building Congress Construction for Development; In-House Publishing: Cape Town, South Africa, 2008.

4. Havinga, L.; Colenbrander, B.; Schellen, H. Heritage significance and the identification of attributes to preserve in a sustainable refurbishment. J. Cult. Heritage 2020, 43, 282-293. [CrossRef]

5. Ornelas, C.; Miranda Guedes, J.; Sousa, F.; Breda-Vázquez, I. Supporting Residential Built Heritage Rehabilitation through an Integrated Assessment. Int. J. Archit. Herit. 2020, 14, 1-14. [CrossRef]

6. UNESCO. The Hangzhou Declaration: Placing Culture at the Heart of Sustainable Development Policies; UNESCO: Hangzhou, China, 2013.

7. UNESCO. Policy for the Integration of a Sustainable Development Perspective into the Processes of the World Heritage Convention; World Heritage and Sustainable Development; UNESCO: Paris, France, 2015; pp. 1-18.

8. Icomos. The Paris Declaration on Heritage as a Driver of Development; Icomos: Paris, France, 2011; pp. 1-6.

9. Icomos. Principles for the Analysis, Conservation and Structural Restoration of Architectural Heritage; Icomos: Victoria Falls, Zimbabwe, 2003; pp. 3-6.

10. Icomos. The Valletta Principles for the Safeguarding and Management of Historic Cities, Towns and Urban Areas; Icomos: La Valletta, Malta, 2011; pp. 1-18. ISBN 9781509033294.

11. Australia Icomos. The Burra Charter-The Australia ICOMOS Charter for Places of Cultural Significance; Icomos: Burra, Australia, 2013.

12. Council of Europe. The European Charter of the Architectural Heritage; Council of Europe: Amsterdam, The Netherlands, 1975.

13. Gonçalves, J.; Mateus, R.; Silvestre, J.D. Mapping Professional Practice Challenges in Built Heritage, Professionalism in the Built Heritage Sector. In Proceedings of the International Conference on Professionalism in the Built Heritage Sector, Arenberg Castle, Leuven, Belgium, 5-8 February 2018; CRC Press: Boca Raton, FL, USA, 2019; p. 125.

14. Perovic, M.; Coffey, V.; Kajewski, S.; Madan, A. Unravelling heritage challenges: Three case studies. J. Cult. Heritage Manag. Sustain. Dev. 2016, 6, 330-344. [CrossRef]

15. Ashley, K.S.; Osmani, M.; Emmitt, S.; Mallinson, M.; Mallinson, H. Assessing stakeholders' perspectives towards the conservation of the built heritage of Suakin, Sudan. Int. J. Heritage Stud. 2014, 21, 674-697. [CrossRef]

16. Roy, D.; Kalidindi, S.N. Critical challenges in management of heritage conservation projects in India. J. Cult. Heritage Manag. Sustain. Dev. 2017, 7, 290-307. [CrossRef]

17. Gonçalves, J.; Mateus, R.; Silvestre, J.; Roders, A. Going beyond Good Intentions for the Sustainable Conservation of Built Heritage: A Systematic Literature Review. Sustainability 2020, 12, 9649. [CrossRef]

18. Ajzen, I. The theory of planned behaviour. Organ. Behav. Hum. Decis. Processes 1991, 50, 179-211. [CrossRef]

19. Ajzen, I. From intentions to actions: A theory of planned behavior. In Action-Control: From Cognitions to Behavior; Springer: Berlin/Heidelberg, Germany, 1985; pp. 11-39.

20. Ajzen, I. Behavioral Interventions Based on the Theory of Planned Behavior. Res. Policy 2002, 8, 1-6.

21. Ghany, M.G.; Strader, D.B.; Thomas, D.L.; Seeff, L.B. Diagnosis, management, and treatment of hepatitis C: An update. Hepatology 2008, 49, 1335-1374. [CrossRef]

22. De Bruin, M.; Sheeran, P.; Kok, G.; Hiemstra, A.; Prins, J.M.; Hospers, H.J.; Van Breukelen, G. Self-regulatory processes mediate the intention-behavior relation for adherence and exercise behaviors. Health Psychol. 2012, 31, 695-703. [CrossRef] [PubMed]

23. Conner, M.; Rodgers, W.; Murray, T. Conscientiousness and the Intention-Behavior Relationship: Predicting Exercise Behavior. J. Sport Exerc. Psychol. 2007, 29, 518-533. [CrossRef]

24. Budden, J.S.; Sagarin, B.J. Implementation intentions, occupational stress, and the exercise intention-behavior relationship. J. Occup. Health Psychol. 2007, 12, 391-401. [CrossRef]

25. Paul, J.; Modi, A.; Patel, J. Predicting green product consumption using theory of planned behavior and reasoned action. J. Retail. Consum. Serv. 2016, 29, 123-134. [CrossRef]

26. Wang, P.; Liu, Q.; Qi, Y. Factors influencing sustainable consumption behaviors: A survey of the rural residents in China. J. Clean. Prod. 2014, 63, 152-165. [CrossRef]

27. van Hooft, E.; Born, M.; Taris, T.; Van Der Flier, H.; Blonk, R.W. Bridging the gap between intentions and behavior: Implementation intentions, action control, and procrastination. J. Vocat. Behav. 2005, 66, 238-256. [CrossRef]

28. Shirokova, G.; Osiyevskyy, O.; Bogatyreva, K. Exploring the intention-behavior link in student entrepreneurship: Moderating effects of individual and environmental characteristics. Eur. Manag. J. 2016, 34, 386-399. [CrossRef]

29. Sang, P.; Yao, H.; Zhang, L.; Wang, S.; Wang, Y.; Liu, J. Influencing factors of consumers' willingness to purchase green housing: A survey from Shandong Province, China. Environ. Dev. Sustain. 2019, 22, 4267-4287. [CrossRef] 
30. Du Toit, J.; Wagner, C.; Fletcher, L. Socio-Spatial Factors Affecting Household Recycling in Townhouses in Pretoria, South Africa. Sustainiablity 2017, 9, 2033. [CrossRef]

31. Ortiz, M.A.; Bluyssen, P.M. Proof-of-concept of a questionnaire to understand occupants' comfort and energy behaviours: First results on home occupant archetypes. Build. Environ. 2018, 134, 47-58. [CrossRef]

32. Zhang, Y.; Wang, L. Influence of Sustainable Development by Tourists' Place Emotion: Analysis of the Multiply Mediating Effect of Attitude. Sustainability 2019, 11, 1384. [CrossRef]

33. Ramkissoon, H.; Uysal, M.S. The effects of perceived authenticity, information search behaviour, motivation and destination imagery on cultural behavioural intentions of tourists. Curr. Issues Tour. 2011, 14, 537-562. [CrossRef]

34. Ramkissoon, H.; Uysal, M. Testing the Role of Authenticity in Cultural Tourism Consumption: A Case of Mauritius. Tour. Anal. 2010, 15, 571-583. [CrossRef]

35. Yuan, Q.; Song, H.; Chen, N.; Shang, W. Roles of Tourism Involvement and Place Attachment in Determining Residents' Attitudes Toward Industrial Heritage Tourism in a Resource-Exhausted City in China. Sustainability 2019, 11, 5151. [CrossRef]

36. Markström, E.; Bystedt, A.; Fredriksson, M.; Sandberg, D. Perceptions of Swedish Architects and Contractors for the Use of Bio-Based Building Materials. In Proceedings of the COST Action FP1407 2nd Conference: Innovative Production Technologies and Increased Wood Products Recycling and Reuse, Brno, Czech Republic, 29-30 September 2016; Mendel University in Brno: Brno, Czech Republic, 2016; pp. 19-20.

37. Lee, E.; Allen, A.; Kim, B. Interior Design Practitioner Motivations for Specifying Sustainable Materials: Applying the Theory of Planned Behavior to Residential Design. J. Inter. Des. 2013, 38, 1-16. [CrossRef]

38. Li, J.; Tam, V.W.; Zuo, J.; Zhu, J. Designers' attitude and behaviour towards construction waste minimization by design: A study in Shenzhen, China. Resour. Conserv. Recycl. 2015, 105, 29-35. [CrossRef]

39. Gonçalves, J.; Mateus, R.; Silvestre, J.D.; Roders, A.P.; Bragança, L. Attitudes matter: Measuring the intention-behaviour gap in built heritage conservation. Sustain. Cities Soc. 2021, 70, 102913. [CrossRef]

40. Gregory-Smith, D.; Wells, V.K.; Manika, D.; McElroy, D.J. An environmental social marketing intervention in cultural heritage tourism: A realist evaluation. J. Sustain. Tour. 2019, 25, 174-191. [CrossRef]

41. Lwoga, N.B. Tourism employment and local residents' engagement in the conservation of the built heritage in Zanzibar Stone Town in Tanzania. Wit Trans. Ecol. Environ. 2016, 201, 43-55. [CrossRef]

42. Ajzen, I.; Fishbein, M. Predicting and Changing Behavior the Reasoned Action Approach; Taylor \& Francis: Abingdon on Thames, UK, 2010.

43. Gonçalves, J.; Mateus, R.; Silvestre, J.; Bragança, L.; Pereira Roders, A. Building passport for the sustainable conservation of built heritage. J. Archit. Conserv. 2021, in press.

44. Monumentnummer: 532226 Priorij Emmaus Diependaalsedijk 17A $3601 \mathrm{GH}$ te Maarssen. Available online: https: // monumentenregister.cultureelerfgoed.nl/monumenten/532226 (accessed on 14 January 2021).

45. Ajzen, I. Constructing a TPB Questionnaire: Conceptual and Methodological Considerations. 2002. Available online: https: / / people.umass.edu/aizen/tpb.html (accessed on 14 January 2021).

46. Kuipers, M.C.; De Jonge, W. Designing from Heritage: Strategies for Conservation and Conversion; TU Delft: Delft, The Netherlands, 2017.

47. Hair, J.F.; Black, W.C.; Babin, B.J.; Anderson, R.E.; Tatham, R.L. Multivariate Data Analysis, 6th ed.; Pearson Prentice Hall: Hoboken, NJ, USA, 2006.

48. Nunnally, J.C.; Bernstein, I.H. Psychological Theory; McGraw-Hill: New York, NY, USA, 1994.

49. De Brito, J.; Pereira, C.; Silvestre, J.D.; Flores-Colen, I. Expert Knowledge-Based Inspection Systems; Springer: Berlin/Heidelberg, Germany, 2020.

50. Gonçalves, J.; Mateus, R.; Silvestre, J.D. Comparative Analysis of Inspection and Diagnosis Tools for Ancient Buildings; Springer: Berlin/Heidelberg, Germany, 2018; pp. 289-298.

51. Van Hees, R.P.; Naldini, S. MDCS-A System for Damage Identification and Monitoring, Preventive Conservation-From Climate and Damage Monitoring to a Systemic and Integrated Approach. In Proceedings of the International WTA-PRECOM3OS Symposium, Leuven, Belgium, 3-5 April 2019; CRC Press: Boca Raton, FL, USA, 2020; p. 113.

52. Sheeran, P.; Webb, T.L. The Intention-Behavior Gap. Soc. Personalit. Psychol. Compass 2016, 10, 503-518. [CrossRef]

53. Sheeran, P. Intention-Behavior Relations: A Conceptual and Empirical Review European Review of Social Psychology. Eur. Rev. Soc. Psychol. 2002, 12, 37-41. [CrossRef]

54. Pereira-Roders, A.R. Re-Architecture: Lifespan Rehabilitation of Built Heritage; Technische Universiteit Eindhoven: Eindhoven, The Netherlands, 2004; pp. 253-258.

55. Prochaska, J.O.; DiClemente, C.C. Stages and processes of self-change of smoking: Toward an integrative model of change. J. Consult. Clin. Psychol. 1983, 51, 390. [CrossRef] [PubMed] 